О.Н. МИНУШКИН ${ }^{1}$, Е.Г. БУРДИНА ${ }^{2}$, Е.В. НОВОЖЕНОВА ${ }^{3}$

${ }_{1}^{1}$ ФГБУ ДПО ЦГМА Управления делами Президента РФ, Москва

2 ФГБУ «Поликлиника №3 Управления делами Президента РФ»

3 ФГБУ «Поликлиника №1 Управления делами Президента РФ»

\title{
БИЛИАРНЫЙ СЛАДЖ:
}

\section{РЕШЕНHЫЕ И HEPEШЕHНЫЕ ВОПРОСЫ}

В статье представлены международные материалы по изучению проблемы билиарного сладжа (БС). Авторы делятся и собственными данными на основании проведенных исследований (одна группа составила 1107 пациентов с БС; вторая 208 пациентов с разными формами БС; третья группа - 40 пациентов с естественным течением БС при отсутствии фармакологического воздействия; четвертая - 60 пациентов, по 20 пациентов каждого типа БС) с использованием препарата УДХК Эксхол 500 мг №50 и спазмолитика Спарекс 200 мг №30. Назначение исходной дозы 15 мг/кг/сут препарата Эксхол было эффективно в 97\% случаях, и купирование БС достигнуто за 12 недель. Скорость купирования БС зависела от типа (1-й - 4 недели, 2-3-й типы - 8-12 недель).

Ключевые слова: билиарный сладж, УДХК, мебеверин, Эксхол, Спарекс.

\section{O.N. MINUSHKIN ${ }^{1}$, E.G. BURDINA ${ }^{2}$, E.V. NOVOZHENOVA ${ }^{3}$}

${ }^{1}$ Central State Medical Academy of the Administrative Department of the President of the Russian Federation

${ }^{2}$ Outpatient Clinic No 3 of the Administrative Department of the President of the Russian Federation

${ }^{3}$ Outpatient Clinic No 1 of the Administrative Department of the President of the Russian Federation

BILIARY SLUDGE: SOLVED AND UNRESOLVED ISSUES

The article presents international materials on studying the issue of biliary sludge (BS). The authors also share their own data resulting from conducted studies, where the first group included 1107 patients with BS; the second - 208 patients with different forms of BS; the third group - 40 patients with regular course of BS, in the absence of pharmacological influence; the fourth group - 60 patients (20 patients for each type of BS) with UDCA Exhol $500 \mathrm{mg}$ No. 50 and antispasmodic agent Sparex $200 \mathrm{mg}$ No 30. Intake of Exhol at an initial dose of $15 \mathrm{mg} / \mathrm{kg} /$ day was effective in $97 \%$ of cases and BS elimination was achieved in 12 weeks. The BS elimination rate depended on its type ( $1^{\text {st }}-4$ weeks, $2-3^{\text {rd }}$ types $-8-12$ weeks).

Keywords: Biliary sludge, UDCA, mebeverine, Exhol, sparex.

онятие о билиарном сладже желчного пузыря появилось в 70-е гг. прошлого века и характеризовалось как любая неоднородность желчи, выявляемая ультразвуковым исследованием.

По характеру изменений внутрипузырной желчи, получаемой при УЗИ, выделяют три варианта БС:

1-й вариант - взвесь мелких гиперэхогенных частиц, смещаемых при изменении положения тела и не дающих «акустической тени», - микролитиаз;

2-й вариант - наличие слабовыраженного уровня замазкообразной (эхопозитивной) желчи: расслоение желчи на эхонегативную и эхопозитивную (замазкообразную) фракции без «акустической тени»;

3-й вариант - замазкообразная желчь в виде подвижных и/или фиксированных сгустков без «акустической тени».

Эти варианты представлены на рисунках 1 (схема) и 2 (ультразвуковые варианты).

Внедрение такого деления на варианты БС явилось основанием к пересмотру существовавших тогда классификаций желчнокаменной болезни (ЖКБ). Так, в 1974 г. D. Small предложил выделять 5 стадий ЖКБ:

1-я стадия включала генетические, биохимические и метаболические дефекты, приводящие к перенасыщению желчи холестерином; 2-я стадия - химическая, которая устанавливала биохимические признаки «литогенной желчи»;

3-я стадия - физическая, при которой создавались условия, реализующие литогенную желчь в кристаллы холестерина;

4-я стадия - формирование холестериновых камней;

5-я стадия - появление и прогрессирование симптомов холелитиаза.

Выделение стадий ЖКБ позволяло установить ранние фазы заболевания и патогенетически воздействовать на ту стадию, в которой осуществлялась диагностика. Уже тогда было понятно, что болезнь имеет многофакторный генез и не ограничивается только нарушением метаболизма холестерина [1]. В 1982 г. Х.Х. Мансуров [2] предложил более простую и удобную для клинической практики классификацию ЖКБ, выделив в ней всего 3 стадии болезни:

1. Физико-химическую стадию (в которой осуществляется секреция литогенной желчи и начинают формироваться микролиты). По существу эта стадия включает формирование билиарного сладжа желчного пузыря (ЖП).

2. Стадию формирования желчных камней.

3. Стадию формирования и прогрессирования клинических проявлений и осложнений в т. ч.

И наконец, III Съезд гастроэнтерологов России (2008) принял и утвердил современную классификацию ЖКБ [3], 
в которой выделяют 4 стадии, в т. ч. и ту, которой посвящено настоящее сообщение:

- І стадия - начальная (предкаменная):

- Густая неоднородная желчь.

- Формирование билиарного сладжа:

- микролиты,

- замазкообразная желчь,

- сочетание замазкообразной желчи с микролитами.

II стадия - формирование желчных камней.

III стадия - хронический рецидивирующий калькулезный холецистит.

- IV стадия - осложнения.

Из представленных материалов видно, что отечественная клиническая наука внесла в изучение ЖКБ значительный вклад. Процесс камнеобразования в билиарных путях достаточно длительный, но обратимый, если правильно определены факторы, способствующие камнеобразованию. Это положение является самым важным еще и потому, что основным методом оказания медицинской помощи в РФ является диспансеризация, включающая раннее выявление и оказание патогенетического лечения на всех этапах медицинского обслуживания больного. Это важно еще и потому, что ЖКБ по распространенности занимает 3-е место в общей структуре медицинской помощи в РФ; значительная часть больных подвергается хирургическому лечению, а это само по себе может представлять опасность для больного.

Таким образом, подводя итог этой части настоящего сообщения, следует признать, что ЖКБ является распространенным заболеванием, составляя в среднем в разных регионах мира 10-15\%, в России - 3-12\% (с преобладанием поражения женщин и лиц зрелого возраста от 40 до 60 лет) [4]. Говоря о начальной стадии ЖКБ - билиарном сладже (БС), его частота в общей популяции составляет около 4\%; у пациентов с жалобами на неблагополучие органов пищеварения - около 7,5\% и у пациентов с жалобами, характерными для неблагополучия билиарного типа - около 24-55\% [1]. В последние годы многими авторами фиксируется явная тенденция к росту частоты формирования БС [5].

\section{Причины формирования БС (факторы риска)}

\section{1. Генетические:}

- снижение активности холестерин-7-альфа-гидроксилазы, которая регулирует скорость синтеза желчных кислот,

- наличие определенного генотипа апо-липопротеина $\mathrm{E}$ (содержащего аллель апоЕ4), который приводит к повышенному риску развития ЖКБ).

2. Демографические (женский пол, белая раса, пожилой возраст, географическое место проживания).

\section{3. Диетические:}

голодание,

- низкокалорийная диета,

- парентеральное питание.

Эти факторы способствуют снижению сократительной способности желчного пузыря и спазму сфинктера Одди (СO).

\section{4. Медицинские:}

- гастродуоденостаз (затрудняющий пассаж желчи по билиарным путям),

- дистальная резекция желудка, приводящая к снижению синтеза холецистокинина и снижению сократительной способности желчного пузыря; этому же способствует и повреждение двигательных ветвей n. Vagus,

- хронический бескаменный холецистит,

- холестероз желчного пузыря,

- аномалии желчного пузыря и билиарных протоков,

- папиллосфинктеротомия,

- гемиколэктомия,

болезни кишечника.

\section{Рисунок 1. Схематическая выраженность билиарного сладжа на УЗи}

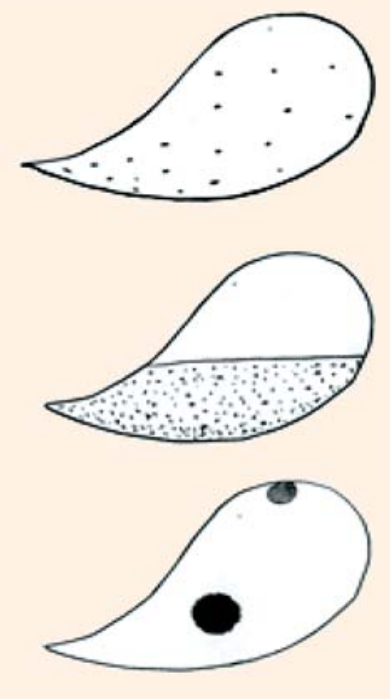

1. Взвесь гиперэхогенных частиц

2. Неоднородная, слабоподвижная желчь с формированием уровня

3. Замазкообразная желчь в виде подвижных и/или фиксированных сгустков

Рисунок 2. Ультразвуковые варианты билиарного сладжа

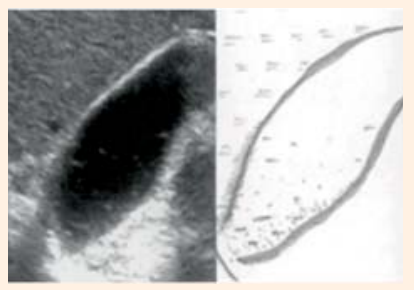

1-й тип БС Содержимое пузыря негомогенное за счет подвижной слабоэхогенной взвеси

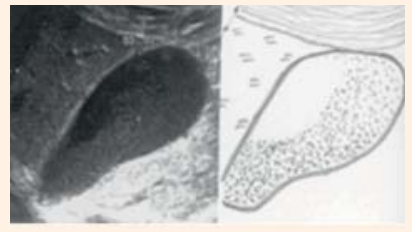

\section{2-й тип БС}

Уровень замазкообразной, малоподвижной взвеси, которая занимает более половины объема пузыря

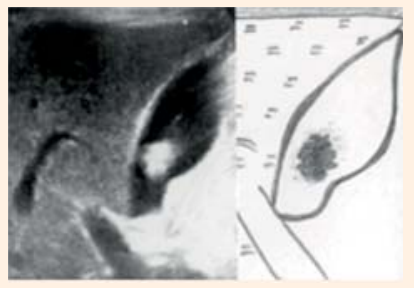

\section{3-й тип БС}

Сгусток желчи на фоне взвеси гиперэхогенных частиц 
Эта группа факторов приводит к снижению сократительной способности ЖП или к нарушению энтерогепатической циркуляции желчи, конечным итогом реализации которых является формирование БС.

\section{5. Гематологические факторы:}

гемолиз,

анемии,

- функциональная гипербилирубинемия.

Эта группа факторов реализуется через формирование «билирубинового» БС (составляющего приблизительно $10 \%$ больных).

6. Беременность (реализующая эффект формирования БС через нарушение пассажа желчи - внутрибрюшная гипертензия, гиперэстрогенемию и гиперхолестеринемию).

7. Патология печени: реализующая свой эффект через нарушение (изменение) спектра желчных кислот; через гиперхолестеринемию, через нарушение экскреции фосфолипидов в желчные протоки.

8. Лекарственная терапия (оральные контрацептивы, цефалоспорины, препараты кальция, фибраты, прием наркотических препаратов).

Эффекты реализуются разными механизмами:

- через нарушение синтеза холестерина,

- нарушение синтеза и обмена желчных кислот с повышением литогенности желчи,

- спазм сфинктера Одди [4, 5].

Выделение причин (факторов риска) образования БС является важным, т. к. их поиск и определение формируют наиболее эффективную и целенаправленную тактику ведения таких больных с нередким разрывом (прерыванием) перехода билиарного осадка в камни, а это является главной целью диагностики и лечения ЖКБ.

Рассматривая факторы риска образования БС, следует отметить, что все они могут быть сгруппированы по следующим основным патогенетическим признакам:

I. Метаболические (ведущие к нарушению состава желчи и способствующие осаждению отдельных компонентов, формируя сладж).

II. Механические (препятствующие, затрудняющие пассаж желчи и способствующие формированию сладжа). В этом отношении главным фактором является снижение сократительной способности ЖП или изменение градиента давления, затрудняющее его опорожнение.

Можно рассмотреть также иное классификационное деление факторов риска:

А. Способствующие формированию БС факторы.

Б. Разрешающие факторы.

И наконец, третий патогенетический подход - это количество действующих факторов:

а) множественные факторы,

б) единичные факторы.

В данном случае задача клинициста заключается в том, чтобы уменьшить количество факторов, способствующих формированию БС. Если говорить о характере лечения, то в этой ситуации оно всегда будет симптоматическим.

Но! Эта задача дальнейших исследований, обобщений, раздумий.

\section{АКТУАЛЬНОСТЬ ПРОБЛЕМЫ БС}

І. БС подлежит активному выявлению.

II. Так как существуют факторы образования БС, то необходимо формирование групп риска, за которыми следует осуществлять диспансерное наблюдение.

III. Интенсивность (частота и сроки) наблюдения должны зависеть от того, какие факторы риска преобладают в данной конкретной группе наблюдения:

- способствующие образованию БС,

- реализующие образование БС.

IV. Так как процесс формирования БС длительный и многостадийный, то это открывает широкую перспективу как первичной, так и вторичной профилактики БС.

V. Если больных с БС активно не наблюдать и не лечить, то это приводит к тяжелым последствиям:

- у 5-20\% больных формируются желчные (холестериновые и билирубиновые) камни;

- у 50-93\% больных формируется: дисфункция сфинктера Одди, сфинктерит, стеноз сфинктера Одди:

- билиарный панкреатит (у 30-33\% больных),

- острый холецистит (у 2-3\% больных),

- рецидивирующий холангит (0,5\% больных),

- блокированный желчный пузырь с присоединени-

ем активного микробного (гнойного) воспаления - у $2-5 \%[6,7]$.

Все вышеизложенное является серьезным основанием не только для теоретического рассмотрения проблемы БС, но и для практических действий, направленных на снижение и предупреждение осложнений билиарного сладжа.

\section{РЕЗУЛЬТАТЫ СОБСТВЕННЫХ ИССЛЕДОВАНИЙ}

В настоящих исследованиях были поставлены различные задачи.

I. В первом - установить частоту выявления БС у больных, находящихся на обслуживании в поликлинике №3 медицинского центра УД Президента РФ.

Так как феномен БС ультразвуковой, то мы учитывали результаты УЗИ, проведенные больным, находящимся на учете. Всего за год прошло обследование 1107 больных (преобладали пациенты женского пола 59,3\%). Частота БС составила 9,1\% от среднегодовой численности прикрепленного контингента. В структуре БС преобладал 1-й тип (взвесь эхопозитивных частиц) - 58,6\%; 2-й тип - (густая желчь с уровнем) - 18,3\%, 3-й тип (сгустки желчи) - 23,1\% (рис. 3). Если говорить о клинических проявлениях, то основным симптомом была боль в правом подреберье 43,3\%, вторым симптомом была билиарная диспепсия $3,8 \%$ и сочетание боли и билиарной диспепсии - 24\%. Бессимптомное течение БС зарегистрировано у $30,9 \%$ больных (преимущественно у больных с 1-м типом БС).

Это позволило сделать следующий вывод:

БС при диспансерном обследовании встречается достаточно часто - 9,1\%, и у 30,9\% из них он протекает бессимптомно, что заставляет обследовать прикрепленных больных активно с обязательным включением в комплекс обследования УЗИ. 


\section{Рисунок 3. Структура билиарного сладжа (по данным УЗИ, 208 больных)}

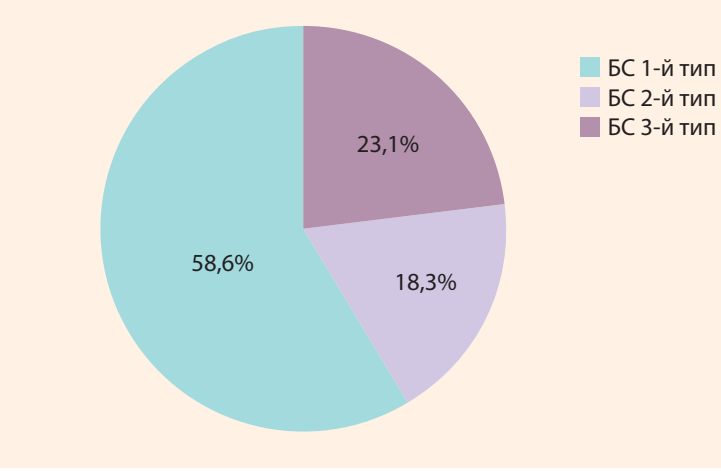

II. Во втором исследовании основной задачей стало динамическое исследование больных с БС с целью установления факторов формирования, интенсивности, прогрессирования и частоты перехода осадка в камни.

Для этого в группу исследования было включено 208 пациентов, находящихся на учете с диагнозом «желчнокаменная болезнь в стадии БС». Кроме УЗИ, оценивались клинические проявления, биохимическое исследование крови (АЛТ, АСТ, билирубин, ЩФ, ГГТ, холестерин) для исключения или подтверждения патологии печени; изучалась сократительная способность желчного пузыря (за норму принят коэффициент опорожнения от 50 до 70\% первоначального объема). Проводились гематологические исследования (при этом установлено: гемолитическая анемия - 11 больных, В12-дефицитная анемия - 6, синдром Жильбера - 2 больных, в общей сложности - 19 больных, что составило 9,1\% - это совпадает со среднестатистическими данными).

Основную группу составили пациенты женского пола (55,3\%, n = 115, p < 0,05), причем 1-й тип БС превалировал у женщин - 61,7\%, 2-й и 3-й типы распределились (М/ж) приблизительно одинаково. Эти данные сопоставимы с результатами других исследований $[8,9]$.

При анализе полученных данных выявлены основные клинические проявления БС:

боли в правом подреберье ( $\mathrm{n}=90,43,3 \%)$;

- сочетание болей и билиарной диспепсии (горечь во рту, тошнота, отрыжка) как самостоятельный, единственный симптом фиксировалось у 8 больных - 3,8\%;

бессимптомное течение $(\mathrm{n}=60,28,9 \%)$.

Анализ симптоматики в зависимости от типа БС показал, что бессимптомное течение чаще (46,7\%) встречалось у больных с 1-м типом БС, а боль - у больных с 3-м и 2-м типами (рис. 4). Это становится понятным при сравнительном анализе морфологии БС: структуры, составляющие 2-й и 3-й типы, проходя по билиарным путям и через сфинктерную систему, оказывают раздражение и приводят, как правило, к спастическим реакциям разной интенсивности, а они формируют клинические проявления. Этого мало для того, чтобы заподозрить «сладж» и его тип, но достаточно для того, чтобы начать обследование.
III. В третьем исследовании главная задача - проследить динамику БС у больных с естественным течением (при отсутствии лечебного воздействия).

Группу наблюдаемых составили 40 больных, которым по разным причинам лечения не проводилось (отказ от лечения, непереносимость предлагаемых препаратов и др.). Сроки наблюдения больных составили от 1 года до 10 лет (в среднем 6,5 года). Средний возраст больных составил 56,7 года; женщин - 21, мужчин - 19. Типы БС: 1-й тип - 14 больных, 2-й тип - 10 больных, 3-й тип - 16 больных.

Из представленной таблицы видно, что спонтанное купирование БС зафиксировано у 5 больных (12,5\%). Это были больные с единичными факторами риска: больные с острой кишечной, печеночной, желчепузырной патологией и временным нарушением пассажа желчи по «билиарному дереву» (4 больных - острый энтероколит, 1 больной - с острым гепатитом). У 15 больных (37,5\%) прогрессирования БС за 5 лет наблюдения не отмечено, сам феномен БС носил преходящий характер и связан был с патологией кишечника.У 19 больных (47,5\%) зафиксировано прогрессирование БС в камни, при этом 11 больных оперированы с развитием в разные сроки постхолецистэктомного синдрома.

Рассмотрев факторы риска динамики БС в камни, мы установили, что такими факторами являются: оперированный желудок, патология ЖП, ведущая к снижению его сократительной способности, патология кишечника, нарушающая энтерогепатическую циркуляцию желчных

\section{Таблица. Исходы течения билиарного сладжа без} лечения

\begin{tabular}{l|c}
\hline \multicolumn{1}{c|}{ Всего $(\mathrm{n}=40)$} & $n(\%)$ \\
\hline Самопроизвольное исчезновение & $5(12,5)$ \\
\hline Отсутствие динамики & $15(37,5)$ \\
\hline Отрицательная динамика: & $20(50,0)$ \\
Переход БС в другой тип & $1(2,5)$ \\
Формирование конкрементов & $19(47,5)$
\end{tabular}

\section{Рисунок 4. Результаты изучения клинических проявлений у больных с БС}

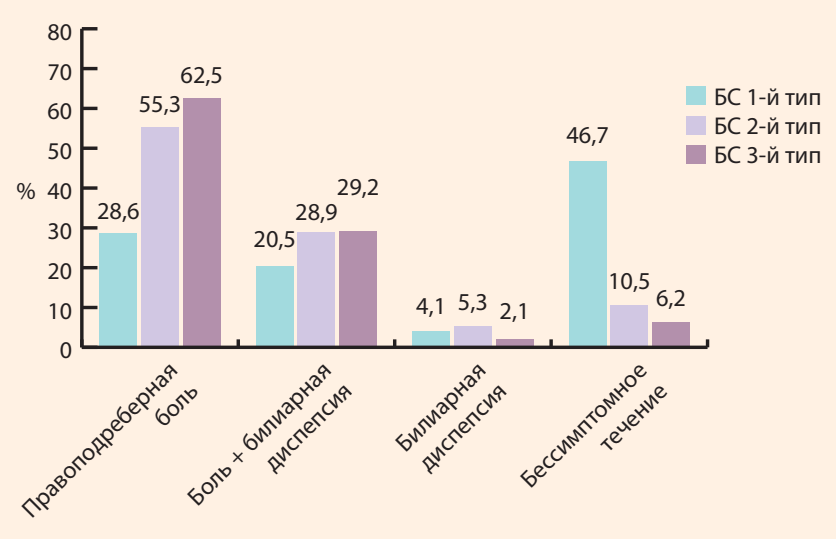


кислот, сахарный диабет, гиперлипидемия. Особенное значение имеет сочетание разных факторов риска образования БС.

Представленные данные подтверждают необходимость лечения всех типов БС при их установлении, т. к. это предотвратит трансформацию БС в камни и иные осложнения БС.

\section{Лечение больных с установленным БС}

\section{А. Общие принципы}

- уменьшение поступления холестерина с пищей;

- снижение продукции холестерина гепатоцитами;

- повышение синтеза первичных желчных кислот;

- увеличение экскреции холестерина с желчью;

- восстановление сократительной способности желчно-

го пузыря при ее снижении;

- восстановление градиента давления (при сохраненной сократительной функции ЖП) либо восстановление транзита пищевого химуса по кишечнику, если нарушенный транзит является причиной нарушенного градиента давления;

- лечение сопутствующей патологии, если она является причиной, формирующей БС.

\section{Б. Некоторые частные вопросы лечения}

Несмотря на то что актуальность ЖКБ не вызывает сомнений и единственной стадией болезни, при которой сохраняется возможность излечения, является стадия билиарного сладжа, считать вопросы лечения БС хорошо разработанными преждевременно.

\section{Диета}

Так, в диетическом лечении одним из главных принципов является «ограничение жиров», но даже этот постулат спорен, т. к. их ограничение сопровождается снижением синтеза липазы, нарушением синтеза и усвоения жирорастворимых витаминов.

Второй важный постулат - преобладание растительной клетчатки - способствует повышению синтеза панкреатической липазы. НО! снижает ее активность на 50\%.

Так что наиболее рациональным питанием является хорошо сбалансированная диета с достаточным содержанием белков, жиров и углеводов, но более частая (5-6 раз в день, малыми порциями).

\section{Лекарственная терапия}

Определение тактики лечения и выбор препаратов для снижения синтеза холестерина - вопрос неоднозначный, т. к. подавить (уменьшить) синтез холестерина мы можем, но эффективность этого сомнительна.

Фармакотерапия, которая на сегодня не подлежит сомнению, - это назначение препаратов:

口 для регуляции моторики желчного пузыря, сфинктеров, желчных путей;

- регуляции градиента давления;

восстановления функциональной активности печеночной клетки (гепатопротекторы), выбор которых максимально эффективно осуществляется на основании классификации О.Н. Минушкина и др. [10].
Базисными лекарственными средствами в лечении БС являются препараты урсодезоксихолевой кислоты (УДХК), которые способны воздействовать на основные звенья билиарного литогенеза и уменьшать или полностью купировать литогенные свойства желчи [11].

IV. Задачей четвертого исследования была оценка эффективности и безопасности комплексной схемы с применением препаратов УДХК (Эксхол) и спазмолитика (Спарекс) по результатам лечения пациентов с тремя вариантами БС.

После заполнения информированного согласия, согласно критериям включения/исключения, в исследование были включены 60 пациентов с билиарным сладжем (по 20 человек с каждым типом). Соотношение мужчин и женщин было 1:2, средний возраст 52,4 \pm 1,2 года с разбросом от 20 до 80 лет. Наличие осадка и сократительная способность ЖП определялись по данным УЗИ, в качестве раздражителя использовался сорбит (20 г на 100 мл жидкости). Сократительная функция ЖП считалась сохраненной при коэффициенте от 50 до 70\% от первоначального объема (ниже этих показателей - сократительная способность ЖП снижена; выше - спастическая). Рентгенологическое исследование должно было ответить обязательно на вопрос - есть/нет гастродуоденостаз; биохимическое исследование крови - есть/нет патология печени; общий анализ крови - подтвердить/отвергнуть анемию (при повышении уровня непрямого билирубина - отвергнуть/подтвердить гемолиз). Для лечения использовался препарат урсодезоксихолевой кислоты Эксхол 500 мг в дозе 15 мг/кг массы тела в сутки, 1 раз в сутки, 8 недель, в качестве спазмолитика - препарат Спарекс 200 мг х 2 раза в сутки 4-6 недель (при спастическом варианте дисфункции желчного пузыря, таких больных было 9).

\section{РЕЗУЛЬТАТЫ ЛЕЧЕНИЯ ЧЕТВЕРТОЙ ГРУППЫ ПАЦИЕНТОВ}

Результаты влияния лечения на динамику клинических проявлений у пациентов с БС, которым была определена терапия препаратами Эксхол 500 мг и Спарекс 200 мг, представлены на рисунке 5.

\section{Рисунок 5. Клиническая симптоматика (первые 2 мес.)}

Влияние лечения на динамику клинических проявлений

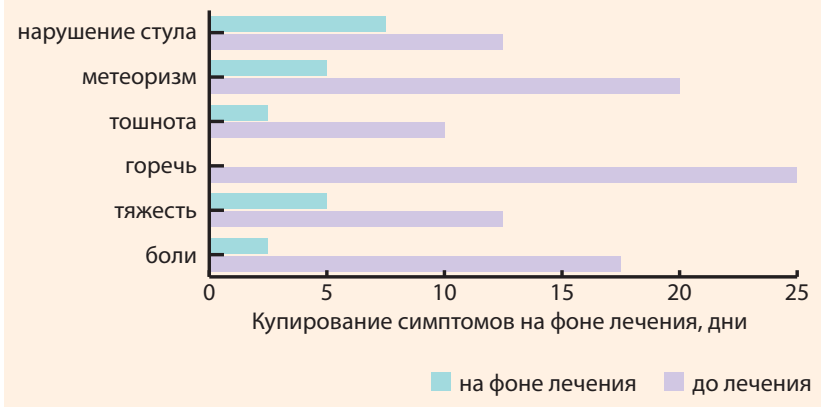


Рисунок 6. Влияние лечения на динамику БС (8 недель)

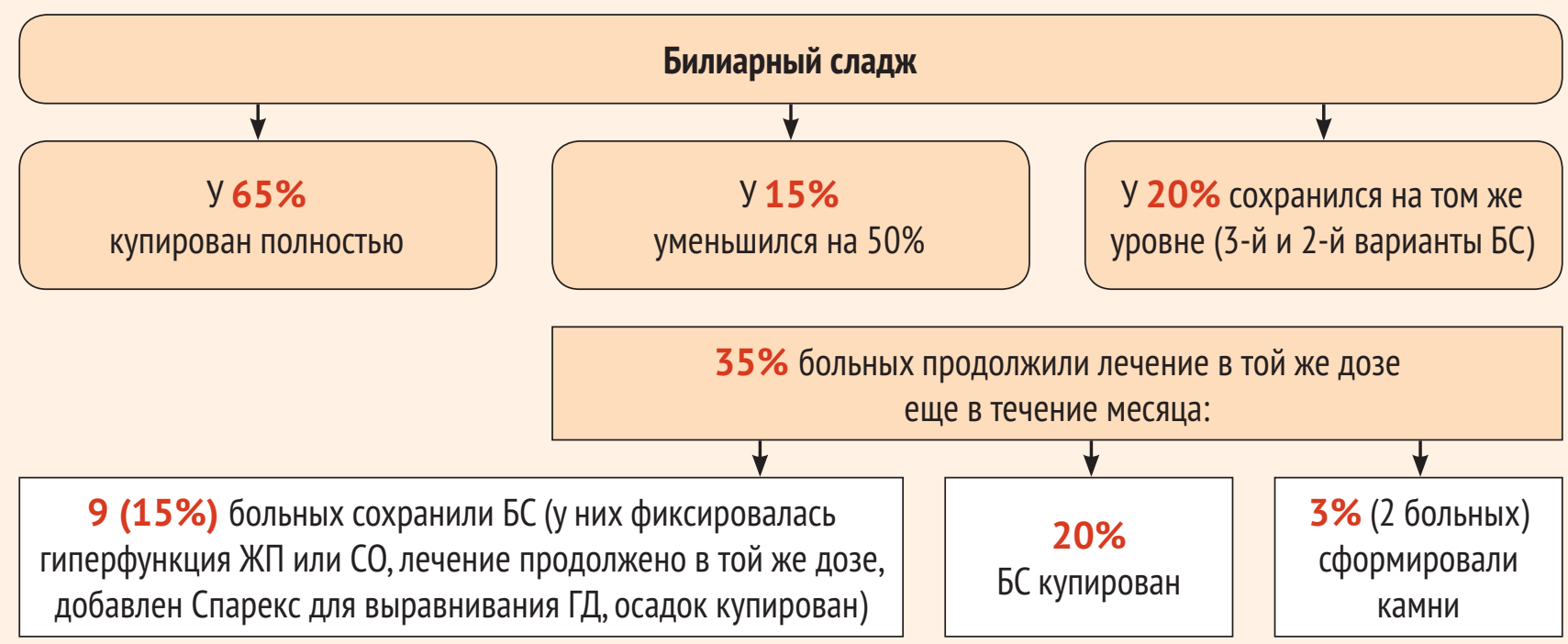

\section{9 больных требовали продолжения лечения}

І либо в тех же дозах,

либо в дозах более высоких,

либо использовался сочетанный вариант лечения
Как видно из представленных данных, клинический симптомокомплекс был купирован в первые 10 дней лечения. Проведенный анализ УЗИ показал, что это было связано не с купированием БС, а в основном с нормализацией моторики ЖКТ (значительно уменьшился метеоризм, у половины больных нормализовался стул). Причем это относится ко всем отделам «кишечной трубки» (уменьшение боли и тяжести в эпигастрии; нормализация тонуса кишечника и стула). Следует отметить, что эти данные характеризуют купирование симптомов, а у больных с сохраненной симптоматикой отмечено уменьшение степени ее выраженности.
Влияние лечения на динамику БС препаратом Эксхол представлено на рисунке 6.

Представленные данные убедительно показали, что препарат Эксхол 500 мг в данной клинической ситуации эффективен в лечении БС, его форма выпуска - делимая таблетка 500 мг позволяет сократить количество принимаемых таблеток и за счет этого повышает приверженность к лечению у пациента. За 8 недель лечения БС купирован у 65\% пациентов. Причем у пациентов с 1-м типом БС и дозой УДХК 15 мг/Кг массы тела достаточно 4 недель лечения, 2-й и 3-й типы БС требуют более продолжительного (3 месяца, по нашим данным) либо ком-

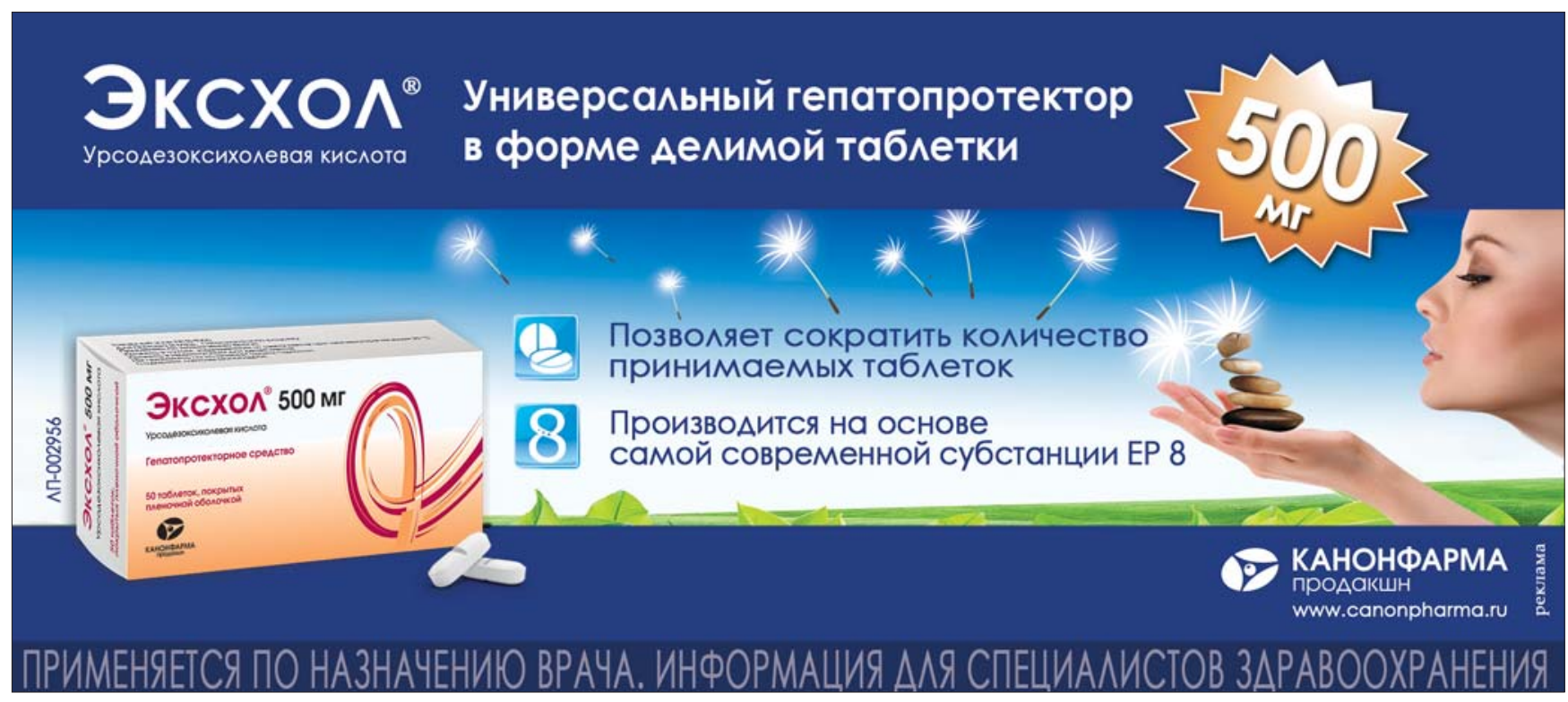


бинированного лечения (при спазме - спазмолитики, при патологии печени - гепатопротекторы, при дисбактериозе - корректоры дисбиоза). Так, у 9 больных (15\%) был установлен либо гипертонус ЖП, либо гипертонус $\mathrm{CO}$, и то и другое требовало введения в комплекс лечения спазмолитиков. Мы использовали Спарекс в суточной дозе 400 мг. Отметим удобство применения данного препарата, т. к. благодаря матричной технологии высвобождения действующего вещества он поддерживает постоянно эффективную дозу в течение не менее 12 часов. Таким образом, эффект купирования сладжа был получен, побочные эффекты зарегистрированы не были. Двое пациентов (3\%) были прооперированы, т. к. сформировались камни «билирубинового» характера.

\section{ЗАКЛЮЧЕНИЕ}

Методом патогенетической терапии БС является применение препаратов урсодезоксихолевой кислоты. Отечественный препарат Эксхол 500 мг мы оценили как весьма эффективный в лечении БС. Для того чтобы сократить продолжительность основного курса лечения, назначена исходная доза препарата 15 мг/кг. Продолжительность лечения для разных типов БС варьируется: для 1-го типа БС достаточно 4 недели, для 2-го и 3-го типов БС - не менее 8-12 недель. В зависимости от ведущих факторов риска БС лечение может быть комби- нированным: при спастическом варианте сократительной функции ЖП, при спазме СО - в комбинации должны быть использованы спазмолитики; в приведенном нами исследовании с успехом использован препарат Спарекс.

\section{Ранняя диагностика БС, эффективное лечение, достаточное по продолжительности, устранение (уменьшение) факторов риска образования БС могут предупредить переход стадии сладжа в стадию камнеобразования и изменить прогноз течения желчнокаменной болезни}

При повреждении печени, например хроническом гепатите, в комбинацию должны входить печеночные протекторы, выбор которых зависит от характера патологии печени. В целом имеющиеся данные подтверждают благоприятный прогноз того, что ранняя диагностика БС, эффективное лечение, достаточное по продолжительности, устранение (уменьшение) факторов риска образования БС могут предупредить переход стадии сладжа в стадию камнеобразования и изменить прогноз течения желчнокаменной болезни.

Конфликт интересов: авторы заявляют об отсутствии конфликта интересов в ходе написания данной статьи.

\section{ЛИТЕРАТУРА}

1. Ильченко А.А. Болезни желчного пузыря и желчных путей. 2011, 358. /llchenko AA. Gallbladder and bile duct disorders, 2011, 358.

2. Мансуров X.X. Желчнокаменная болезнь. 1991, 222 c. /Mansurov HH. Gallstone disease, 1991, 222 pages.

3. Ильченко А.А. Классификация ЖКБ. Российский журнал гастроэнтерологии, гепа тологии, колопроктологии, 2002, 5, 99./ Ilchenko AA. Gallstone disease classification. Rossiyskiy Zhurnal Gastroenterologii, Gepatologii, Koloproktologii, 2002, 5, p. 99.

4. Минушкин О.Н., Бурдина Е.Г., Новоженова Е.В. Билиарный сладж. Эпидемиология, факторы риска формирования, диагностика, лечебные подходы. Медицинский алфавит, 19, 2017, 2./ Minushkin ON, Burdina EG, Novozhenova EV. Biliary Sludge. Epidemiology, risk factors for formation, diagnosis, treatment approaches. Meditsinskiy Alfavit, 19, 2017, 2.
5. Новоженова Е.В. Билиарный сладж: факторы риска, диагностика, лечение, прогноз: дисс. ... канд. мед. наук, 2017. /Novozhenova EV. Biliary sludge: risk factors, diagnosis, treatment, prognosis, diss. of Ph.D., 2017.

6. Ильченко А.А., Делюкина О.В. Клиническое значение билиарного сладжа. Consilium Medicum, 2005, 2: 28-32. /llchenko AA, Delyukina OV. Clinical significance of biliary sludge. Journal Consilium Medicum, 2005, 2 28-32.

7. Минушкин О.Н. и др. Билиарный сладж: диагностика и лечение в условиях поликлиники. Экспериментальная и клиническая гастроэнтерология, 2013, 9, 14-20./Minushkin ON, et al. Biliary Sludge: diagnosis and treatment in outpatient clinic settings. Journal Eksperimentalnaya i Klinicheskaya Gastroenterologiya, 2013, 9, 14-20.

8. Маев И.В. и др. Актуальность терапии пациентов с билиарным сладжем. Клинические перспективы гастроэнтерологии, гепатологии, 2013, 1: 3-10 /Maev IV, et al. Immediacy of the therapy of patients with biliary sludge. Journal Klinicheskiye Perspektivy Gastroenterologii, Gepatologii, 2013, 1, 3-10

9. Вихрова Т.В. Билиарный сладж и его клиническое значение: автореф. дисс. ... канд. мед. наук, M., 2003. Nikhrova TV. Biliary sludge and its clinical significance. Extended abstract of PhD in medicine Dissertation. Moscow, 2003.

10. Минушкин О.Н. и др. Патология печени и место Лаеннека в лечении. Методическое пособие, 2017, 11 с. /Minushkin ON, et al. The hepatopathy and the role of Laennec in the treatment. Methodical guide, 2017, 11 pp.

11. Минушкин О.Н., Елизаветина Г.А., Иванова О.И., Шапошникова О.Ф. Урсодезоксихолевая кислота в лечении больных с билиарным сладжем. Эффективная фармакотерапия, 2012, 3: 10-13./Minushkin ON, Elizavetina GA Ivanova OI, Shaposhnikova OF. Ursodeoxycholic acid in the treatment of patients with biliary sludge, Journal Effektivnaya Farmakoterapiya, 2012, 3, p. 10-13.

\section{СВЕДЕНИЯ ОБ АВТОРАХ:}

Минушкин Олег Николаевич - д.м.н., профессор, заведующий кафедрой гастроэнтерологии ФГБУ ДПО ЦГМА Управления делами Президента РФ, Москва

Бурдина Елена Григорьевна - доктор медицинских наук, научный руководитель поликлиники №2 УДП РФ, заведующая отделением гастроэнтерологии, ультразвуковых и эндоскопических исследований поликлиники №3 УДП РФ

Новоженова Елена Вячеславовна - К.М.Н., кафедра гастроэнтерологии ЦГМА УДП РФ, врач-терапевт, поликлиника №1 УДП РФ 